\title{
Characterization of Rain Specific Attenuation and Frequency Scaling Method for Satellite Communication in South Korea
}

\author{
Sujan Shrestha and Dong-You Choi \\ Department of Information and Communications Engineering, Chosun University, Gwangju, Republic of Korea \\ Correspondence should be addressed to Dong-You Choi; dychoi@chosun.ac.kr
}

Received 1 September 2016; Accepted 31 October 2016; Published 3 January 2017

Academic Editor: Stefania Bonafoni

Copyright ( 2017 S. Shrestha and D.-Y. Choi. This is an open access article distributed under the Creative Commons Attribution License, which permits unrestricted use, distribution, and reproduction in any medium, provided the original work is properly cited.

\begin{abstract}
The attenuation induced by rain is prominent in the satellite communication at Ku and Ka bands. The paper studied the empirical determination of the power law coefficients which support the calculation of specific attenuation from the knowledge of rain rate at $\mathrm{Ku}$ and $\mathrm{Ka}$ band for Koreasat 6 and COMS1 in South Korea that are based on the three years of measurement. Rain rate data was measured through OTT Parsivel which shows the rain rate of about $50 \mathrm{~mm} / \mathrm{hr}$ and attenuation of 10.7, 11.6, and $11.3 \mathrm{~dB}$ for $12.25,19.8$, and $20.73 \mathrm{GHz}$, respectively, for $0.01 \%$ of the time for the combined values of rain rate and rain attenuation statistics. Comparing with the measured data illustrates the suitability for estimation of signal attenuation in Ku and Ka band whose validation is done through the comparison with prominent rain attenuation models, namely, ITU-R P.618-12 and ITU-R P. 838-3 with the use of empirically determined coefficient sets. The result indicates the significance of the ITU-R recommended regression coefficients of rain specific attenuation. Furthermore, the overview of predicted year-wise rain attenuation estimation for Ka band in the same link as well as different link is studied which is obtained from the ITU-R P. 618-12 frequency scaling method.
\end{abstract}

\section{Introduction}

Rainfall has been recognized as one of the atmospheric effects that has serious impacts on radio wave propagation [1]. The path attenuation caused by heavy rainfall can result in signals to become indistinguishable from the noise signal of the receiver [2]. The higher frequency bands such as $\mathrm{Ku}$ $(12 / 14 \mathrm{GHz})$ and $\mathrm{Ka}(20 / 30 \mathrm{GHz})$ are most effective in satellite communication and promise future demands of higher data rate services. In this concern, satellite communication plays a crucial role but the atmospheric propagation effects impair the availability and quality of satellite links during the service period [3]. The higher frequencies band has been preferable to provide direct to home (DTH) multimedia services [4]. Rain attenuation in satellite communication systems operating at Ka band frequencies is more severe than usually experienced at lower frequency bands [5]. A number of mitigation techniques have been envisioned and experimented over the years, in an attempt to overcome the problem and to make Ka band satellite applications as commercially viable as those at $\mathrm{Ku}$ band [6]. Direct measurement of rain attenuation for all of the ground terminal locations in an operational network is not practical, so modeling and prediction methods must be used for better estimation of expected attenuation for each location [7]. The methods for the prediction of rain attenuation for a given path have been grouped into two categories, namely, physical and semiempirical approaches. The physical approach considered the path attenuation as an integral of all individual increments of rain attenuation caused by the drops encountered along the path. Unfortunately, rain cannot be described accurately along the path without extensive meteorological database, which does not exist in most regions of the world [8]. In addition, when physical approach is used, then all the input parameters needed for the analysis are not readily available [9]. Most prediction models therefore resort to semiempirical approaches which depend on the two factors, namely, rain rate at a point on the surface of the earth and the effective path length over which the rain can be considered to be homogeneous [10]. The attenuation on any given path depends on the value of specific attenuation, frequency, polarization, temperature, path length, and latitude [11]. When the comparative analyses of the 
various rain attenuation prediction models for earth-space communication have been carried out against the measured results to predictions, the ITU-R P. 618-12 is preferred from both its inherent simplicity and reasonable accuracy, at least for frequencies up to approximately $55 \mathrm{GHz}$ [12]. The short integration time rain rate is an essential input parameter required in prediction models for rain attenuation. In this regard, local prediction model for 1-minute rain rate is analyzed in South Korea, where the modified polynomial shows the predictable accuracy for the estimation of 1-minute rain rate distribution [13-15]. Similarly, rain attenuation had been studied for Koreasat-3 satellite from the database provided by the Yong-in Satellite Control Office where the ITU-R prediction model for earth-space communication is analyzed $[16,17]$. The preliminary bases for estimation of rain attenuation on slant path applicable for Ka band have been studied with the combined values of rain attenuation for three years in South Korea [18]. In this paper, a technique for predicting the rain attenuation of Ka bands satellite signals during rain events at Mokdong-13 na-gil, Yangcheon-gu, Seoul, Republic of Korea, has been presented which is analyzed from the year-to-year variation of rain attenuation database provided by National Radio Research Agency (RRA) and studied for earth-space communication.

The several prominent rain attenuation prediction methods have been studied in [21-29] where the performances of ITU-R method required for the design of earth-space telecommunication systems have been compared. The problem of predicting attenuation by rain is quite difficult, because of nonuniform distribution of rain rate along the entire path length. Most of the models show poor results on severe climates [30]. The best possible estimates given by the available information can be provided by the use of prediction models due to sparse measured data. These measured distributions are compared with those predicted by method currently recommended by the International Telecommunication Union Radio Communication Sector ITU-R P. 618-12 [12], rain attenuation obtained by integrating the specific attenuation along the propagation path as per the ITU-R P. 838-3 [31] approach. Although some research activities are performed for $\mathrm{Ku}$ band satellite link in South Korea region, fewer studies are done for Ka band link. A theoretical study of rain attenuation factor has been performed in South Korea as mentioned in [32], which emphasizes the need of more experimental data for better comparison with the existing rain attenuation models. The techniques in [18] have been further studied which utilizes power law relationship between the effective path length and rain rate at $0.01 \%$ of the time and predicts the attenuation values for other time percentage as per the ITU-R P. 61812 extrapolation approach. The rainfall rate at $0.01 \%$ of the time has been useful parameter for estimation of rain induced attenuation on slant path which can be seen in [33]. The prediction approach requires the statistical features of the signal variation at the location obtained over a long term period, three years in the present case on earth-to-space propagation database at $\mathrm{Ku}$ and $\mathrm{Ka}$ band. This paper studied the result of measured rain attenuation as compared with the cumulative probability distributions of ITU-R P. 618-12
TABLE 1: Regression coefficients obtained from ITU-R P. 838-3 approach [31].

\begin{tabular}{lccc}
\hline Satellite links & $k$ & $\alpha$ & Polarization \\
\hline $12.25 \mathrm{GHz}$ & 0.024205 & 1.151616 & Circular \\
$20.73 \mathrm{GHz}$ & 0.104750 & 1.010399 & Circular \\
$19.8 \mathrm{GHz}$ & 0.094139 & 0.986283 & Vertical \\
\hline
\end{tabular}

and ITU-R P. 838-3 methods and studied the suitable means to characterize the rain attenuation behavior for $\mathrm{Ku}$ and $\mathrm{Ka}$ band satellite communication links. The rest of this paper is organized as follows. Section 2 shows the brief overview of selected rain attenuation models. Experimental system along with proposed approach is described in Section 3. Based on the pertinent models and experimental setup, Section 4 presents the statistical analysis with particular emphasis on predicted and measured rain attenuation along with the frequency scaling technique adopted to predict attenuation values for $20.73,19.8 \mathrm{GHz}$ links from $12.25 \mathrm{GHz}$ for the same and different path, respectively. Finally, conclusions are drawn in Section 5.

\section{Literature Review of Rain Attenuation Models}

The attenuation prediction model consists of three methodologies: firstly, the calculation of specific attenuation [31]; secondly, the calculation of rain height [34]; and, thirdly, the attenuation calculation methodology. Power law form of rain specific attenuation is widely used in calculating rain attenuation statistics. Path attenuation is essentially an integral of individual increments of rain attenuation caused by drops encountered along the path which required the physical approach. Unfortunately, rain cannot be described accurately along the path without extensive meteorological database, which do not exist in most regions of the world. Hence, total attenuation is determined as

$$
A(\mathrm{~dB})=\gamma_{R}(\mathrm{~dB} / \mathrm{km}) \times L_{\mathrm{eff}}(\mathrm{km}),
$$

where $\gamma_{R}(\mathrm{~dB} / \mathrm{km})$ is the specific attenuation and $L_{\text {eff }}(\mathrm{km})$ is the effective path length. $L_{\text {eff }}$ is the length of a hypothetical path obtained from radio data dividing the total attenuation by specific attenuation exceeded for the same percentage of time. The recommendation of the ITU-R P.838-3 [31] establishes the procedure of specific attenuation from the rain intensity. The specific attenuation $\gamma_{R}(\mathrm{~dB} / \mathrm{km})$ is obtained from the rain rate $R(\mathrm{~mm} / \mathrm{h})$ exceeded at $p$ percent of the time using the power law relationship as

$$
\gamma_{R}=k R^{\alpha}
$$

where $k$ and $\alpha$ depend on the frequency and polarization of the electromagnetic wave. The constants appear in recommendation tables of ITU-R P. 838-3 [31] and also can be obtained by interpolation considering a logarithmic scale for $k$ and linear scale for $\alpha$. Most of the existing rain attenuation prediction models used the regression coefficients $k$ and $\alpha$ to estimate the rain attenuation. The calculated regression coefficients are listed in Table 1. 
Secondly, the mean annual rain height is determined through the recommendation of ITU-R P. 839-4 [34] where the $0^{\circ} \mathrm{C}$ isotherm height above mean sea level is obtained through the provided digital map. Thirdly, the attenuation calculation procedures differ as per the applicable methods. As an initial step, ITU-R P. 618-12 [12] has been tested against available field results of the experimental links for earthspace communication at $19.8 \mathrm{GHz}$ for COMS1 and 12.25 , $20.73 \mathrm{GHz}$ for Koreasat 6 satellites. This requires the rain rate at $0.01 \%$ of the time with 1-minute integration, height above sea level of the earth station $(\mathrm{km})$, elevation angle $(\theta)$, the latitude of the earth station $(\varphi)$, and frequency $(\mathrm{GHz})$. Similarly, the calculation of the horizontal reduction and vertical adjustment factors is based on $0.01 \%$ of the time exceedance whose detail approach can be found in [12]. The effective path length can be obtained using ( $3 a$ ), whereas the total rain attenuation at $0.01 \%$ of the time $\left(A_{0.01}\right)$ can be calculated using equation (3b):

$$
\begin{aligned}
L E & =L R v_{0.01} \mathrm{~km} \\
A_{0.01} & =\gamma_{R} L_{E} \mathrm{~dB} .
\end{aligned}
$$

The predicted attenuation exceedances for other time percentages of an average year can be acquired from the value of $A_{0.01}$ using the extrapolation approach as presented in (3c) [12]:

If $p \geq 1 \%$ or $|\varphi| \geq 36^{\circ}, \beta=0$.

If $p<1 \%$ and $|\varphi|<36^{\circ}$ and $\theta \geq 25^{\circ}, \beta=-0.005(|\varphi|-36)$.

Otherwise, $|\varphi|<36^{\circ}$ and $\theta<25^{\circ} ; \beta=-0.005(|\varphi|-36)+$ $1.8-4.25 \sin \theta$.

$$
\begin{aligned}
& A_{p} \\
& =A_{0.01}\left(\frac{p}{0.01}\right)^{-\left(0.655+0.033 \ln (p)-0.045 \ln \left(A_{0.01}\right)-z(1-p) \sin \theta\right)} .
\end{aligned}
$$

In addition, to calculate the effective path length, Simple Attenuation Model (SAM) [35] has been adopted. This model studied the relationship between specific attenuation and rain rate, statistics of the point rainfall intensity, and spatial distribution of rainfall on earth-space communication links operating in the range of 10 to $35 \mathrm{GHz}$. It considers the exponential shape of the rain spatial distribution, which includes the distinction between stratiform and convective rain. The effective path length is calculated from an effective rain height which is expressed by (4a) and (4b). In stratiform rain, with point $R \leq 10 \mathrm{~mm} / \mathrm{hr}$, the rain height is constant and equal to isotherm height above mean sea level whose values is given by ITU-R P. 839-4 [34]. Similarly, in convective rainstorms, when $R>10 \mathrm{~mm} / \mathrm{hr}$, the effective rain height depends on the rain rate because strong storms push rain higher into the atmosphere, lengthening the slant path. The attenuation time series is depicted as [35]

$$
\begin{aligned}
A_{p \%} & =\gamma L_{s} ; \quad R_{p \%} \leq 10 \mathrm{~mm} / \mathrm{hr} \\
L_{s} & =\frac{\left(H_{R}-H_{S}\right)}{\sin \theta},
\end{aligned}
$$

where $A_{p \%}$ and $R_{p \%}$ are the attenuation and rain rate exceeded for $p \%$ of time, $\gamma$ is specific attenuation due to rainfall, $L_{s}$ is slant-path length up to rain height, $H_{R}$ is rain height above mean sea level, $H_{s}$ is station height, and $\theta$ is elevation angle of the top of rain height.

In convective rainstorms, when $R_{p \%}>10 \mathrm{~mm} / \mathrm{hr}$, a modified value of effective path length is used for determination of slant-path attenuation as

$$
\begin{array}{r}
A_{p \%}=\gamma \frac{1-\exp \left[-\alpha b \ln \left(R_{p \%} / 10\right)\right] L_{s} \cos \theta}{\alpha b \ln \left(R_{p \%} / 10\right) \cos \theta} ; \\
R_{p \%}>10 \mathrm{~mm} / \mathrm{hr},
\end{array}
$$

where $b=1 / 22$. Furthermore, the empirical expression for effective rain height $H_{R}$ is given as

$$
H_{R}= \begin{cases}H_{0} ; & R \leq 10 \mathrm{~mm} / \mathrm{hr} \\ H_{0}+\log \left(\frac{R}{10}\right) ; & R>10 \mathrm{~mm} / \mathrm{hr} .\end{cases}
$$

$H_{0}$ is the $0^{\circ} \mathrm{C}$ isotherm height. The detail description on the applicability of this model is described in [35].

\section{Experimental Methods and Measurements}

The experimental setup is installed at Korea Radio Promotion Association building, Mokdong-13 na-gil, Yangcheon-gu, Seoul, Republic of Korea $\left(37^{\circ} 32^{\prime} 45.25^{\prime \prime} \mathrm{N}, 126^{\circ} 52^{\prime} 58.8^{\prime \prime} \mathrm{E}\right)$, by National Radio Research Agency (RRA). The beacon receiver measures the level of $\mathrm{Ku}$ and $\mathrm{Ka}$ bands beacon of the Koreasat 6 satellite at 12.25 and $20.73 \mathrm{GHz}$, respectively, using $1.8 \mathrm{~m}$ antenna whose specification is detailed in Table 2. Similarly, another beacon receiver is installed at the same place to measure the Ka band beacon at $19.8 \mathrm{GHz}$ from COMS 1 using similar sized antenna whose specifications are depicted in Table 3. Both the receivers sample the data at an interval of 10 seconds which are averaged over 1-minute distribution for further statistical analyses. Satellite links have availability of 99.95\% and the schematic for the setup is shown in Figure 1. In addition, an optical disdrometer, OTT Parsivel, is used to measure the rain rates which operates simultaneously with the monitoring system of satellite beacon signal whose specification is also given in Table 2. These antennas were covered with radome to prevent wetting antenna conditions. The received signal levels were sampled every 10 seconds and finally averaged over 1 minute. The three years' rainfall intensities with $99.95 \%$ of the validity of all time were collected by OTT Parsivel, a laser-based optical disdrometer for simultaneous measurement of particle size and velocity of all liquid and solid precipitation, for every 10 seconds whose detail operation is mentioned in [18].

The schematic diagram for system setup is shown in Figure 1.

As shown in Figure 1, the offset parabolic antenna is faced towards Koreasat 6 and COMS 1 satellites. The circularly polarized beacon signal at 12.25, $20.73 \mathrm{GHz}$ from Koreasat 6 and vertically polarized signal at $19.8 \mathrm{GHz}$ were downconverted using separate Low Noise Block Converter (LNBC) which is further described in [18]. The experimental data shows the receive signal level is relatively higher in Ku band as 
TABLE 2: Specifications of the 12.25 and $20.73 \mathrm{GHz}$ links for Koreasat 6 satellite link [19].

\begin{tabular}{|c|c|c|}
\hline Type & Descriptions & Specification \\
\hline \multirow{4}{*}{ System location } & Location & $37.5447^{\circ} \mathrm{N}, 126.8833^{\circ} \mathrm{E}$ \\
\hline & Elevation angle & $45^{\circ}$ \\
\hline & Azimuth angle & $197.5^{\circ}$ \\
\hline & Sea level $(\mathrm{km})$ & 0.055 \\
\hline \multirow{6}{*}{ Receiver antenna } & Antenna type & Offset parabolic \\
\hline & Frequency band (GHz) & $10.95 \sim 31$ \\
\hline & Beacon signal level for clear sky at $12.25 \mathrm{GHz}$ & $-80.5 \mathrm{dBm}$ \\
\hline & Beacon signal level for clear sky at $20.73 \mathrm{GHz}$ & $-38.7 \mathrm{dBm}$ \\
\hline & Polarization & Circular \\
\hline & Gain & $55 \mathrm{~dB} \pm 2 \mathrm{~dB}$ \\
\hline \multirow{6}{*}{ Optical disdrometer } & Type & OTT Parsivel \\
\hline & Measuring area & $54 \mathrm{~cm}^{2}$ \\
\hline & Range of measurement particle size & 0.2 to $25 \mathrm{~mm}$ \\
\hline & Range of measurement velocity & 0.2 to $20 \mathrm{~m} / \mathrm{s}$ \\
\hline & Precipitation intensity & 0.001 to $1200 \mathrm{~mm} / \mathrm{hr}$ \\
\hline & Operating temperature range & $-40^{\circ} \mathrm{C}$ to $+70^{\circ} \mathrm{C}$ \\
\hline
\end{tabular}

TABLE 3: Specifications of the $19.8 \mathrm{GHz}$ link for COMS1 satellite link [19].

\begin{tabular}{|c|c|c|}
\hline Type & Descriptions & Specification \\
\hline \multirow{4}{*}{ System location } & Location & $37.5459^{\circ} \mathrm{N}, 126.883^{\circ} \mathrm{E}$ \\
\hline & Elevation angle & $46.5^{\circ}$ \\
\hline & Azimuth angle & $177.8^{\circ}$ \\
\hline & Sea level $(\mathrm{km})$ & 0.055 \\
\hline \multirow{5}{*}{ Receiver antenna } & Antenna type & Offset parabolic \\
\hline & Frequency band (GHz) & $10.95 \sim 31$ \\
\hline & Beacon signal level for clear sky & $-37.3 \mathrm{dBm}$ \\
\hline & Polarization & Vertical \\
\hline & Gain & $55 \mathrm{~dB} \pm 2 \mathrm{~dB}$ \\
\hline
\end{tabular}

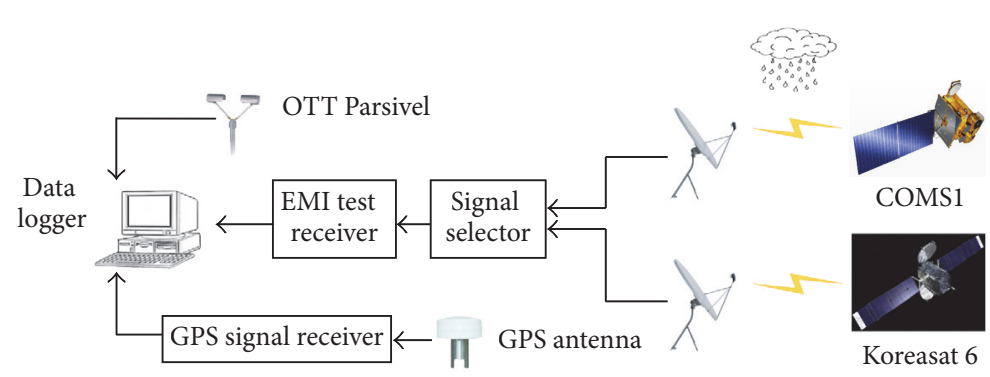

FIGURE 1: Experimental setup for rain attenuation and rain rate measurement [19].

compared to Ka band where the beacon level at $12.25 \mathrm{GHz}$ is relatively higher as compared to 19.8 and $20.73 \mathrm{GHz}$ during no rain condition. This is performed in order to obtain suitable signal-to-noise ratio. This has maintained the relative level of gain and power consumption for the experimental system. Figures 2(a), 2(b), and 2(c) show the sample record of simultaneous measurements of received signal level and rain rate for $12.25,20.73$, and $19.8 \mathrm{GHz}$, respectively. Thus, the corresponding path attenuation is calculated by finding the difference between the RSL during clear sky condition and the RSL during rain for circularly and vertically polarized received signals at various rain rates as follows:

$$
\text { Attenuation }(\mathrm{dB})=\mathrm{RSL}_{\text {clear sky }}-\mathrm{RSL}_{\text {rainy }} \text {. }
$$

The procedure used to obtain slant-path attenuation exceedances for other time instances is further detailed in [18] along with the cumulative distribution of 1-minute rain rate for each year and when combined together. The values for rain attenuation and rain rate in different time series 



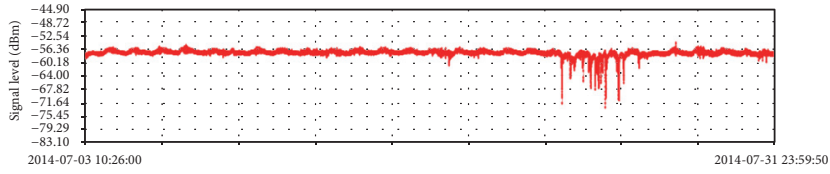

(a)

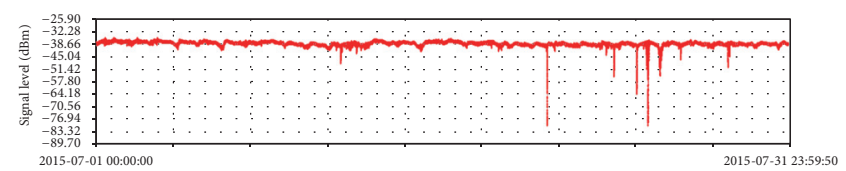

(b)

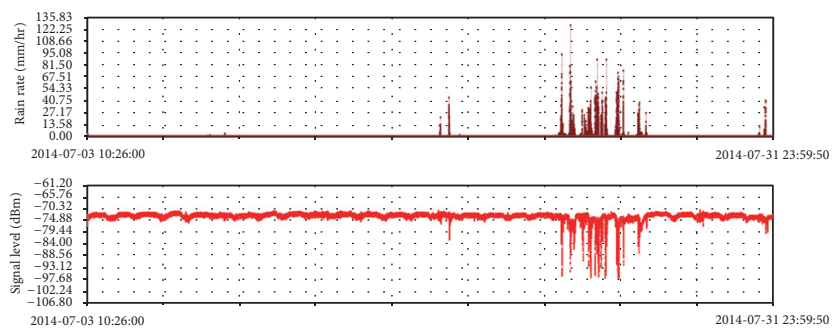

(c)

FIGURE 2: (a) Variation of $12.25 \mathrm{GHz}$ signal level during a rain event [19]. (b) Variation of $20.73 \mathrm{GHz}$ signal level during a rain event [19]. (c) Variation of $19.8 \mathrm{GHz}$ signal level during a rain event [19].

are extracted from the simultaneous measurement of rain attenuation and rain rate at 10 -second intervals. The OTT Parsivel starts recording the rain rate whenever the rain drops pass through the laser beam. These rain rates are converted to 1-minute rain rate instances from the procedure as mentioned in [17]. Similarly, beacon receiver received the beacon signals at fixed signal level for no rain condition. Whenever there is the rainfall, then the corresponding beacon signals are changed from the reference level. Thus, the difference in the signal level determines the required attenuation values. These values are arranged for the 1-minute instance by following the procedure mentioned in [17]. Finally, these data are combined in the descending order and the required 1-minute rain rate and rain attenuation values are determined for $1 \%$ to $0.001 \%$ of the time. For instance, at $0.001 \%$ of the time, 1 -minute rain rate and attenuation values are taken for about $16(((3 * 365 * 24 * 60 * 0.001) / 100)=15.768 \approx 16)$ instances for 3 years of measurement. Similarly, for each year of measurement, the values of about $5(((1 * 365 * 24 * 60 *$ $0.001) / 100)=5.256 \approx 5$ ) instances were considered at the same percentage of time. These instances are calculated by multiplying the number of years, the number of days in a year, and hour and minute in a day, with the required time percentage.

Figure 3 shows the rain attenuation for 12.25, 19.8, and 20.73 GHz frequencies which are obtained on the yearly basis and when combined together from 2013 till 2015. The rain rate is greater in 2013 and 2014 which resulted in higher rain attenuation values of $10.8,12.3 \mathrm{~dB} ; 12.3,11 \mathrm{~dB} ; 12.1,10.2 \mathrm{~dB}$, respectively, for $0.01 \%$ of the time. The combined values of rain attenuation indicate the lower attenuation values at higher time percentages and higher values at lower time percentage. For instance, the attenuation values of 7.9, 10.7,

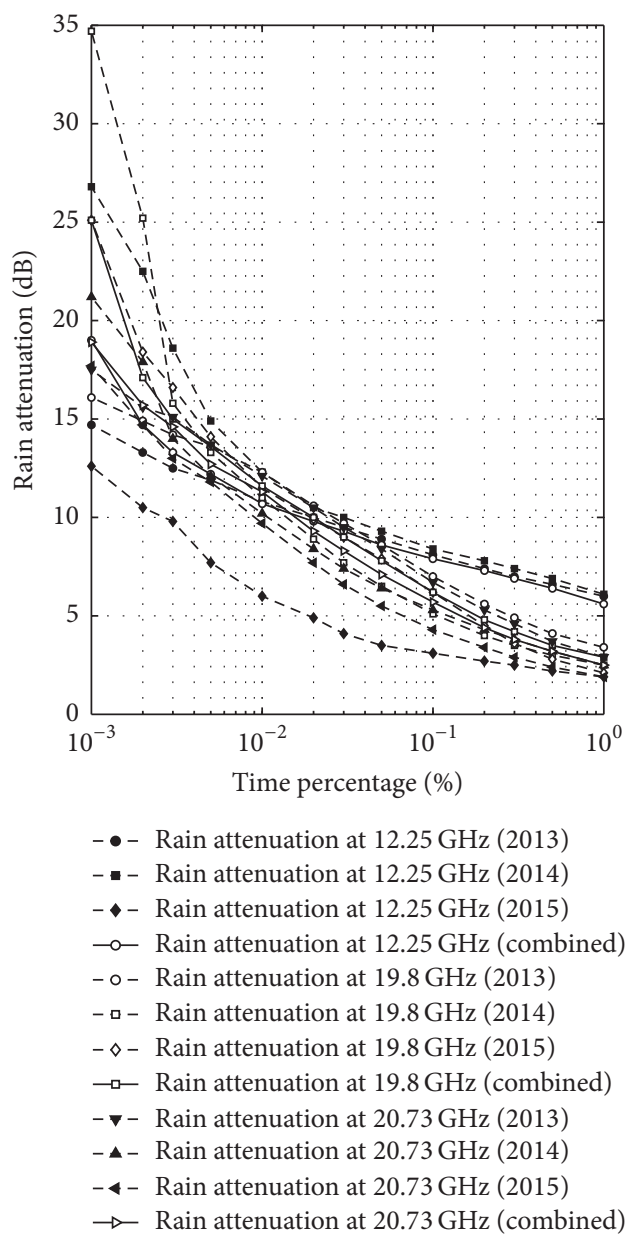

FIgURE 3: Distribution of rain attenuation at Mokdong [19]. 


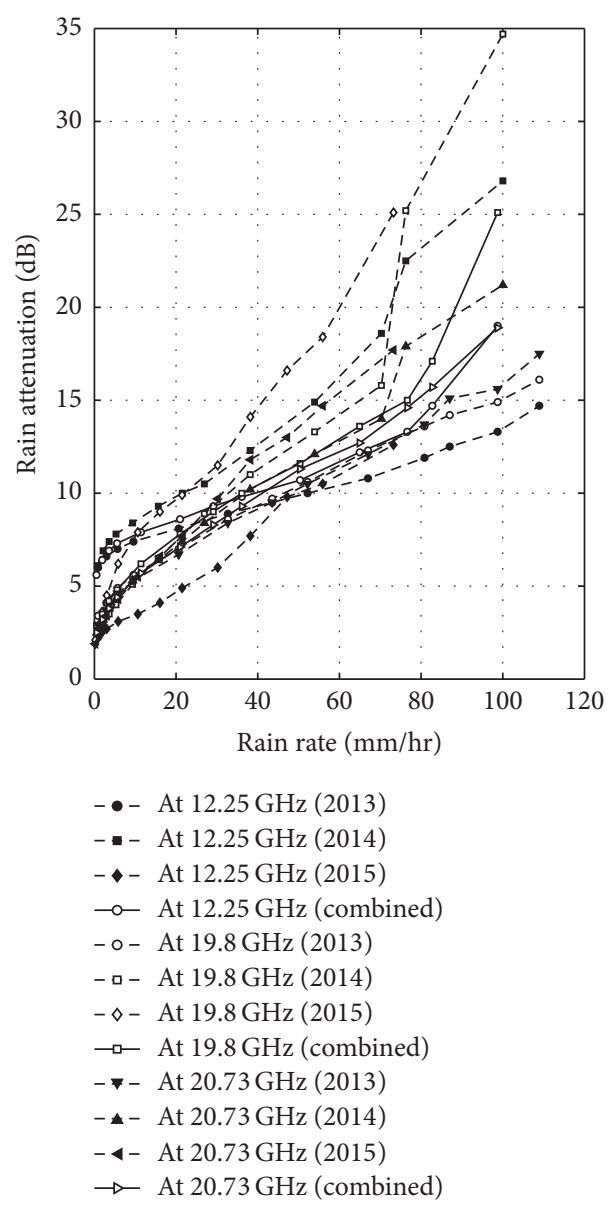

FIgURE 4: Rain attenuation versus rain rate [19].

and $19 \mathrm{~dB} ; 6.2,11.6$, and $25.1 \mathrm{~dB} ; 5.7,11.3$, and $18.9 \mathrm{~dB}$ are observed for $0.1 \%, 0.01 \%$, and $0.001 \%$ of the time, respectively. In addition, year-wise variability of rain rate and rain attenuation are studied further to generalize the use of regression and coefficients $k$ and $\alpha$ value for the better estimation against the measured rain attenuation statistics.

Furthermore, the relation between rain attenuation and rain rate is shown in Figure 4 for three years of measurement along with the combined values. This figure indicates that there is the positive correlation between the rain rate and rain attenuation. Additionally, the experimental procedure carried out by Korea Metrological Administration (KMA) is studied for better analyses of 1-minute rain rate statistics which have been detailed in [18] along with the proposed approach. This emphasizes the need of measurement for rainfall rate provided by RRA with longer duration.

\section{Numerical Results and Discussion}

The analysis presented above is applied here to numerically illustrate the relation between estimated and measured rain attenuation. To this end, the Complementary Cumulative Distribution Function (CCDF) for combined value of rain attenuation for three years at $12.25,19.8$, and $20.73 \mathrm{GHz}$

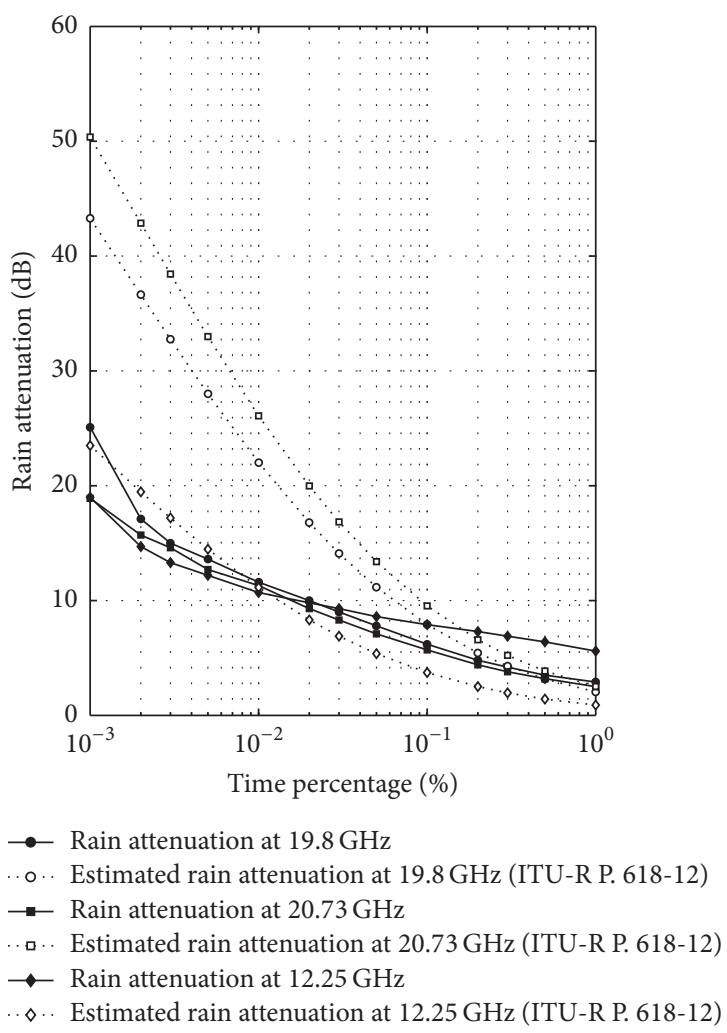

FIgURE 5: Cumulative distribution of rain attenuation as compared with ITU-R P. 618-12 [20].

along with the ITU-R P. 618-12 predicted values is shown in Figure 5 in several time percentages, $p$, at equiprobable exceedance probability $(0.001 \% \leq p \leq 1 \%)$. As shown in the figure, for $12.25 \mathrm{GHz}$ link, ITU-R P. 618-12 model predictions show a close value at $0.01 \%$ of the time but it differs significantly against the rain attenuation CCDF in lower and higher time percentage. At lower time percentage, the difference in prediction is relatively lower as compared to higher time percentage. For instance, the calculated 1minute rain attenuation values are $7.9,10.7$, and $19 \mathrm{~dB}$ while the corresponding ITU-R P. 618-12 estimates 3.73, 11.14, and $23.49 \mathrm{~dB}$ for $0.1 \%, 0.01 \%$, and $0.001 \%$ of the time, respectively, under the combined values of rain attenuation distribution. Under this aspect, the paper presents the discussion of ITUR P. 618-12 which is applied for year-wise rain attenuation database and provides the overview of applicable regression coefficients for $12.25,19.8$, and $20.73 \mathrm{GHz}$ frequencies ranges. The better performance analyses of regression coefficients are done from error calculation in further part.

The measurement is performed for 12.25, 19.8, and $20.73 \mathrm{GHz}$ links in years 2013, 2014, and 2015. Rain rate is plotted against the rain attenuation values arranged for time percentages $1 \%$ to $0.001 \%$ after applying power law so as to generate regression coefficients, $k$ and $\alpha$. The curve fitting tool as presented in MATLAB program was used to determine the empirical expression for effective length, $L_{\text {eff }}$, as mentioned in Table $4 . L_{\text {eff }}$ as obtained from SAM approach is plotted against the respective year-wise rain 
TABLE 4: Regression coefficients for three satellite links [20].

\begin{tabular}{lccccc}
\hline Satellite links & Year & Expression for $L_{\text {eff }}$ & $R^{2}$ & $k$ & $\alpha$ \\
\hline \multirow{4}{*}{$12.25 \mathrm{GHz}$} & 2013 & $5.022 R^{-0.318}$ & 0.6539 & 0.6167 & 0.6323 \\
& 2014 & $4.739 R^{-0.326}$ & 0.5926 & 0.2783 & 0.9692 \\
& 2015 & $3.488 R^{-0.2794}$ & 0.5677 & 0.1778 & 0.9805 \\
\hline \multirow{3}{*}{$20.73 \mathrm{GHz}$} & 2013 & $5.022 R^{-0.318}$ & 0.6539 & 0.2207 & 0.8974 \\
& 2014 & $4.739 R^{-0.326}$ & 0.5926 & 0.1727 & 1.024 \\
& 2015 & $3.488 R^{-0.2794}$ & 0.5677 & 0.3456 & 0.9017 \\
\hline \multirow{3}{*}{$19.8 \mathrm{GHz}$} & 2013 & $5.022 R^{-0.318}$ & 0.6539 & 0.3242 & 0.8015 \\
& 2014 & $4.739 R^{-0.326}$ & 0.5926 & 0.0201 & 1.596 \\
& 2015 & $3.488 R^{-0.2794}$ & 0.5677 & 0.3266 & 0.9854 \\
\hline
\end{tabular}

rate values whose relationship is established by the power law. In addition, the measured rain attenuation is divided by estimated $L_{\text {eff }}$, which is again plotted against the rain rate measurement so as to obtain the required regression coefficients, $k$ and $\alpha$, for specific attenuation, $\gamma_{R}$, at different rain rate. The rain attenuation is thus calculated with the product of empirically generated $k$ and $\alpha$ values, with the estimated $L_{\text {eff }}$. Similarly, the $k$ and $\alpha$ as derived from the procedure explained in ITU-R P. 838-3 whose values as listed in Table 1 are used to obtained attenuation series for ITU-R P. 618-12 extrapolation approach. These values are listed in Table 4.

The correlation coefficient, $R^{2}$, is greater in 2013 for the mentioned three links which indicates the better estimation of rain attenuation from rain rate statistics. This might be due to the use of higher rain rate values at $0.01 \%$ of the time. Hence, comparison of the attenuations obtained from empirically generated $k$ and $\alpha$ along with the ITU-R P. 618-12 prediction method are graphically shown in Figures 6, 7, and 8 under 12.25, 19.8, and $20.73 \mathrm{GHz}$ for 2013, 2014, and 2015 years, respectively.

As noticed from Figures 6, 7, and 8, it is observed that the measured cumulative statistics of rain attenuation are overestimated by ITU-R P. 618-12 for Ka band operation as compared to $\mathrm{Ku}$ band. The overestimation becomes highly pronounced at $20.73 \mathrm{GHz}$. The attenuation obtained after using the empirically derived $k$ and $\alpha$ for specific attenuation $\gamma_{R}$ when multiplied with predicted $L_{\text {eff }}$ generates the better estimation against the measured attenuation values for $\mathrm{Ku}$ and $\mathrm{Ka}$ band frequencies. For instance, the calculated rain attenuation values in $12.25,19.8$, and $20.73 \mathrm{GHz}$ are 8.10 , 10.80 , and $14.70 \mathrm{~dB} ; 8.40,12.30$, and $26.80 \mathrm{~dB} ; 3.10,6.00$, and $12.60 \mathrm{~dB}$ and $7.00,12.30$, and $16.10 \mathrm{~dB} ; 5.10,11.00$, and $34.70 \mathrm{~dB}$; 6.20, 11.50, and $25.10 \mathrm{~dB}$ and 6.70, 12.10, and $17.50 \mathrm{~dB} ; 5.30$, 10.20 , and $21.20 \mathrm{~dB} ; 4.30,9.70$, and $17.70 \mathrm{~dB}$ for 2013,2014 , and 2015 , respectively, at $0.1 \%, 0.01 \%$, and $0.001 \%$ of the time. These values have been overestimated particularly in 19.8 and $20.73 \mathrm{GHz}$ as depicted from Figures 7 and 8. The further error analyses justify the suitability of the mentioned approach.

The rain attenuation prediction model for Earth-satellite link is determined for exceeding time percentages in the range of $0.001 \%$ to $1 \%$. Hence, the percentage errors,



$-\circ$ - Measured rain attenuation in 2013
$\rightarrow$ Rain attenuation obtained from SAM for 2013
$\rightarrow-$ ITU-R P. $618-12$ in 2013
$-\square-$ Measured rain attenuation in 2014
$\rightarrow$ Rain attenuation obtained from SAM for 2014
$\rightarrow$ ITU-R P. $618-12$ in 2014
$-\diamond-$ Measured rain attenuation in 2015
$\leftarrow$ Rain attenuation obtained from SAM for 2015
$\rightarrow-$ ITU-R P. $618-12$ in 2015

FIGURE 6: Comparison between empirical measured data and ITUR P. $618-12$ at $12.25 \mathrm{GHz}$ [20].

$\varepsilon(p)$, between measured Earth-satellite attenuation data ( $\left.A_{\% p \text {,measured }}\right)$ in $\mathrm{dB}$ and the model's predictions $\left(A_{\% p \text {,predicted }}\right)$ in $\mathrm{dB}$ are obtained with expression exceeding time percentage of interest on link at the same probability level, $p$, in the percentage interval $10^{-3} \%<p<1 \%$, as follows:

$$
\varepsilon(p)_{T}=\frac{A_{\% p, \text { predicted }}-A_{\% p, \text { measured }}}{A_{\% p \text {, measured }}} \times 100[\%] .
$$

In addition, chi-square statistic is used to access the methods performance which is given by [36]

$$
\chi^{2}=\sum_{i=1}^{N} \frac{\left(A_{\% p, \text { predicted }, i}-A_{\% p, \text { measured }, i}\right)^{2}}{A_{\% p, \text { predicted }, i}} .
$$

The chi-square statistic is presented against the threshold value which depends on the degree of freedom whose calculated value is 12 for the given observed data. Similarly, for standard deviation, STD and root mean square, and RMS calculation, the approaches followed in [13] have been adopted. As per the recommendation by ITU-R P. 311-15 [37], the ratio of predicted to measured attenuation is calculated and the natural logarithm of these error ratios is used as a test variable. The mean $\left(\mu_{v}\right)$, standard deviation $\left(\sigma_{v}\right)$, and root mean square $\left(\rho_{v}\right)$ of the test variable are then calculated 


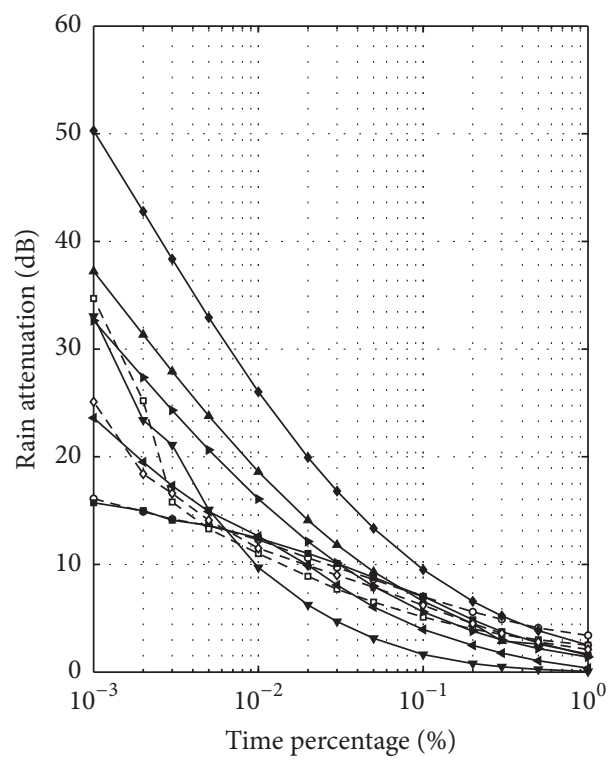

- o- Measured rain attenuation in 2013

- Rain attenuation obtained from SAM in 2013

$\rightarrow$ ITU-R P. 618-12 in 2013

- - - Measured rain attenuation in 2014

$\checkmark$ Rain attenuation obtained from SAM in 2014

$\_$ITU-R P. 618-12 in 2014

- $\diamond-$ Measured rain attenuation in 2015

$\longleftarrow$ Rain attenuation obtained from SAM in 2015

$\rightarrow$ ITU-R P. 618-12 in 2015

Figure 7: Comparison between empirical measured data and ITUR P. $618-12$ at $19.8 \mathrm{GHz}$ [20].

to provide the statistics for prediction methods' comparison which are listed in Tables 5(a), 5(b), and 5(c) along with the chi-square values for $12.25,19.8$, and $20.73 \mathrm{GHz}$ links, respectively, which also shows the evaluation procedures adopted for comparison of prediction methods by the recommendation ITU-R P.311-15 [37].

As shown in Tables 5(a), 5(b), and 5(c), in 12.25, 19.8, and $20.73 \mathrm{GHz}$ links, the proposed empirically derived $k$ and $\alpha$ value when used in specific attenuation calculation so as to obtain desired attenuation values result in lower chances of error as compared to ITU-R P. 618-12 approach when $0.001 \% \leq p \leq 1 \%$ which is justified from lower STD, RMS, $\chi^{2}$ values. In addition, ITU-R P. 618-12 shows underestimation against the measured values in 2014 for $12.25 \mathrm{GHz}$ link. Thus, for all time percentages when $0.001 \% \leq p \leq 1 \%$, for 12.25 , 19.8 , and $20.73 \mathrm{GHz}$, empirically derived $k$ and $\alpha$ value can be used. The numerical values as presented in Tables 5(a), 5(b), and 5(c) justify the suitability of the rain attenuation statistics obtained from the proposed empirically derived $k$ and $\alpha$ value. Furthermore, the attenuation statistics obtained with the use of proposed empirical coefficients $k$ and $\alpha$ result in lower values of $\mu_{v}$ for $12.25,19.8$, and $20.73 \mathrm{GHz}$ links, as per the recommendation of ITU-R P.311-15 [37], which is justified from lower values of $\sigma_{v}$ and $\rho_{v}$. Thus, this emphasizes the suitability of the proposed empirical coefficients for the estimation of rain attenuation in slant path for earth-space communication in $12.25,19.8$, and $20.73 \mathrm{GHz}$ links.

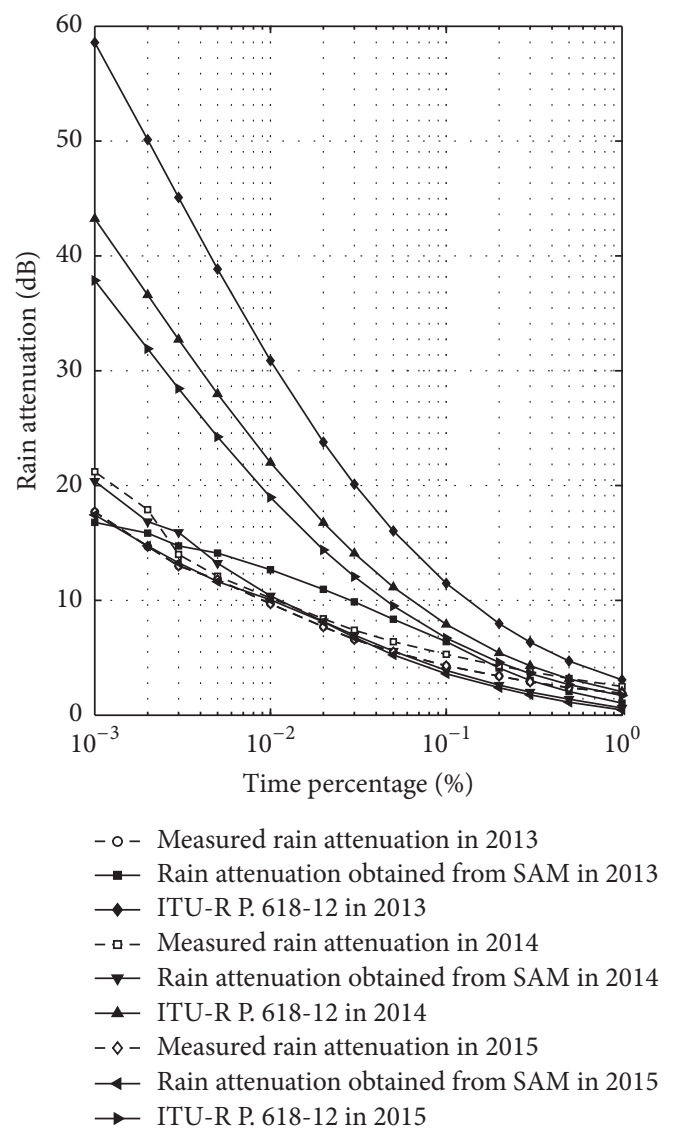

Figure 8: Comparison between empirical measured data and ITUR P. $618-12$ at $20.73 \mathrm{GHz}[20]$.

In order to better visualize the trend of error matrices for the values presented in Tables 5(a)-5(c), we have maintained the plots for relative error, standard deviation, root mean square, and chi-square values in the different time percentages as depicted by Figures 9(a)-9(d), respectively. These figures show that the error matrices decrease and tend to be lesser for the rain attenuation derived from the empirically generated coefficients sets as compared to the rain attenuation statistics obtained from ITU-R P. 618-12 approach.

Furthermore, frequency scaling approach is tested for Ka band along the same and different communication paths. Frequency scaling method provides an alternative to rain attenuation models which are considered to be excellent predictors and provide a means for determining what to expect at a frequency for which there is no data. The analyses performed for year-wise estimation of rain attenuation for 19.8 and $20.73 \mathrm{GHz}$ are depicted in Figures 10 and 11. These show that the estimation is relatively higher against the measured values. Similarly, analyses are performed for combined values of rain attenuation statistics from 2013 till 2015, in which attenuation values at $12.25 \mathrm{GHz}$ are used for frequency scaling purpose and the attenuation series are predicted in 19.8 and $20.73 \mathrm{GHz}$ as depicted in Figure 13.

In order to minimize the error probabilities derived after applying frequency scaling as noticed from Figure 12, 











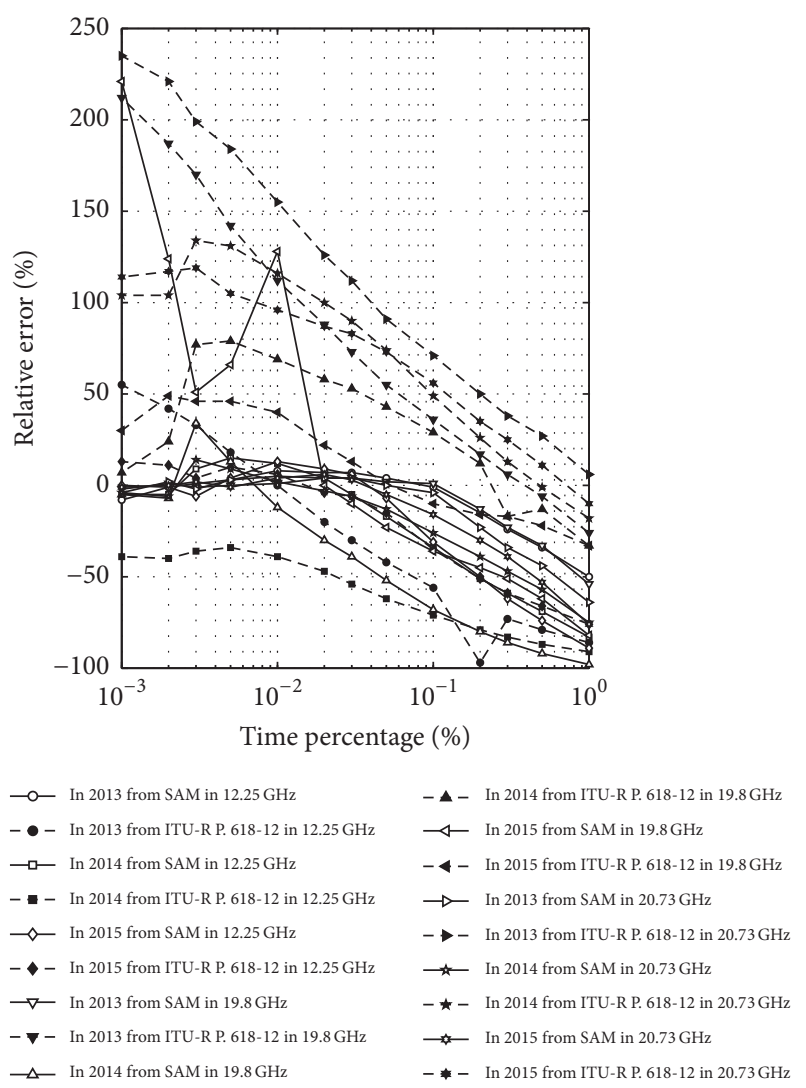

(a)

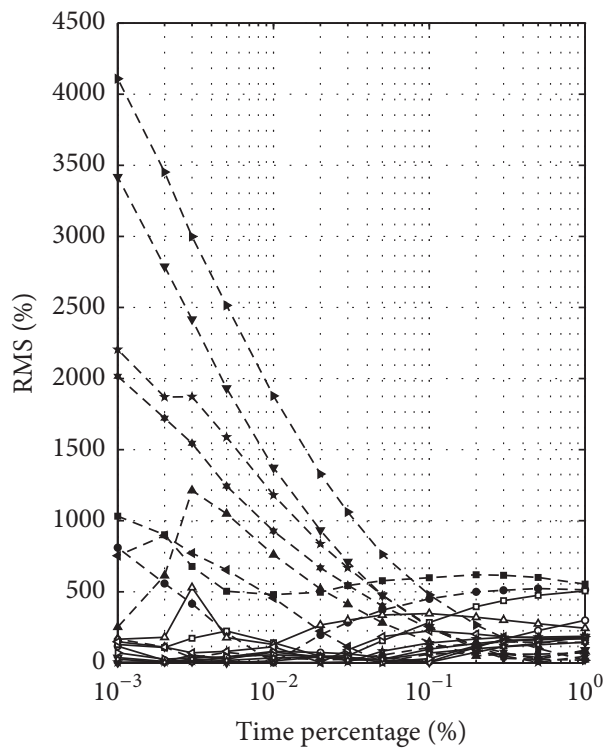

$$
\begin{aligned}
& - \text { - In } 2014 \text { from ITU-R P. } 618-12 \text { in } 19.8 \mathrm{GHz} \\
& \rightarrow-\text { In } 2015 \text { from SAM in } 19.8 \mathrm{GHz} \\
& - \text { In } 2015 \text { from ITU-R P. } 618-12 \text { in } 19.8 \mathrm{GHz} \\
& \rightarrow-\text { In } 2013 \text { from SAM in } 20.73 \mathrm{GHz} \\
& -\star \text { In } 2013 \text { from ITU-R P. } 618-12 \text { in } 20.73 \mathrm{GHz} \text { from SAM in } 20.73 \mathrm{GHz} \\
& \rightarrow-\text { In } 2014 \text { from ITU-R P. } 618-12 \text { in } 20.73 \mathrm{GHz} \\
& - \text { - In } 2015 \text { from SAM in } 20.73 \mathrm{GHz} \\
&
\end{aligned}
$$

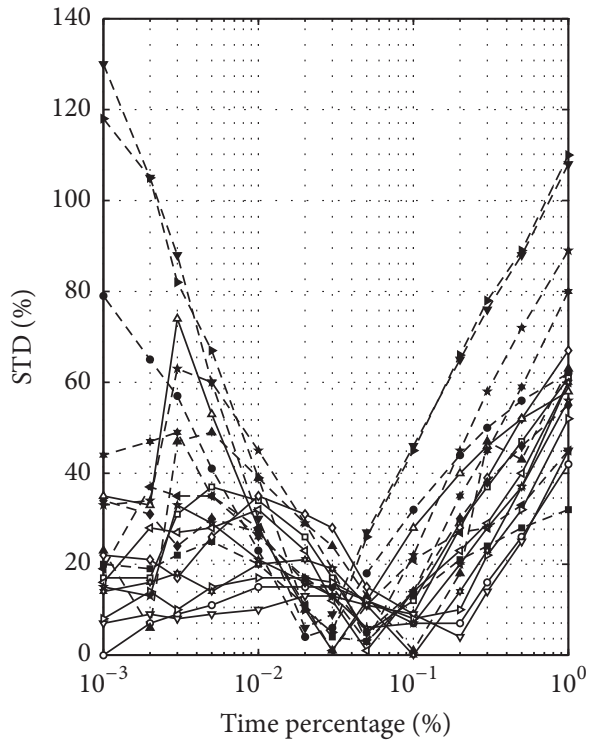

- - In 2013 from SAM in $12.25 \mathrm{GHz}$

- - In 2013 from ITU-R P. $618-12$ in $12.25 \mathrm{GHz}$

- - In 2014 from SAM in $12.25 \mathrm{GHz}$

- - In 2014 from ITU-R P. $618-12$ in $12.25 \mathrm{GHz}$

$\neg$ In 2015 from SAM in $12.25 \mathrm{GHz}$

- - In 2015 from ITU-R P. $618-12$ in $12.25 \mathrm{GHz}$

$\rightarrow$ In 2013 from SAM in $19.8 \mathrm{GHz}$

- - In 2013 from ITU-R P. $618-12$ in $19.8 \mathrm{GHz}$

$\triangle$ - In 2014 from SAM in $19.8 \mathrm{GHz}$

(b)

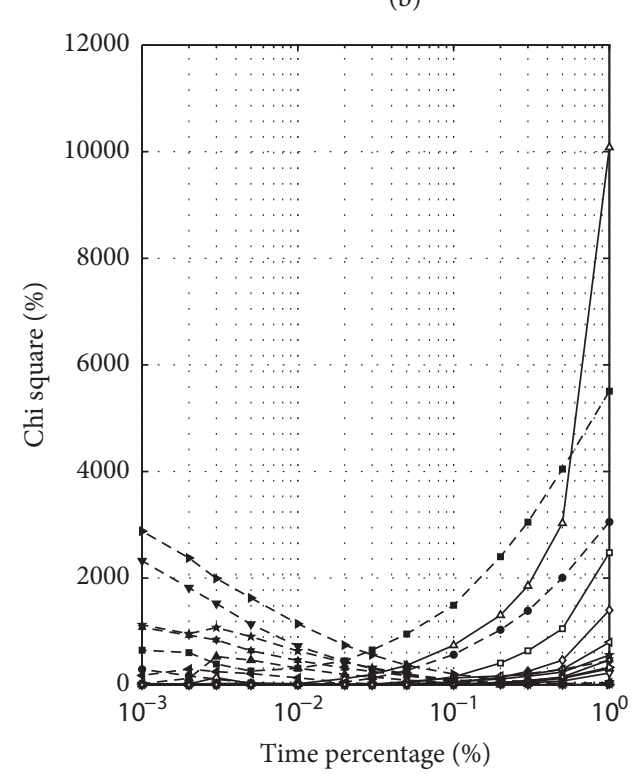

_ - In 2014 from ITU-R P. $618-12$ in $19.8 \mathrm{GHz}$ $\smile$ In 2015 from SAM in $19.8 \mathrm{GHz}$

- 4 - In 2015 from ITU-R P. 618-12 in $19.8 \mathrm{GHz}$ $\rightarrow$ In 2013 from SAM in $20.73 \mathrm{GHz}$

$\longrightarrow$ - In 2013 from ITU-R P. $618-12$ in $20.73 \mathrm{GHz}$

« In 2014 from SAM in $20.73 \mathrm{GHz}$

- $\star$ - In 2014 from ITU-R P. $618-12$ in $20.73 \mathrm{GHz}$

— In 2015 from SAM in $20.73 \mathrm{GHz}$

- \$ - In 2015 from ITU-R P. 618 - 12 in $20.73 \mathrm{GHz}$

\footnotetext{
-0-In 2013 from SAM in $12.25 \mathrm{GHz}$

- • - In 2013 from ITU-R P. $618-12$ in $12.25 \mathrm{GHz}$

- - In 2014 from SAM in $12.25 \mathrm{GHz}$
}

- A - In 2014 from ITU-R P. $618-12$ in $19.8 \mathrm{GHz}$ $\smile$ In 2015 from SAM in $19.8 \mathrm{GHz}$

- 4 - In 2015 from ITU-R P. 618-12 in $19.8 \mathrm{GHz}$ $\rightarrow \quad$ In 2013 from SAM in $20.73 \mathrm{GHz}$

- - In 2013 from ITU-R P. $618-12$ in $20.73 \mathrm{GHz}$

$\star \quad$ In 2014 from SAM in $20.73 \mathrm{GHz}$

- * - In 2014 from ITU-R P. 618-12 in $20.73 \mathrm{GHz}$

— In 2015 from SAM in $20.73 \mathrm{GHz}$

- In 2015 from ITU-R P. $618-12$ in $20.73 \mathrm{GHz}$

Figure 9: (a) Plot of relative error for different time percentages. (b) Plot of standard deviation for different time percentages. (c) Plot of root mean square for different time percentages. (d) Plot of chi square for different time percentages. 


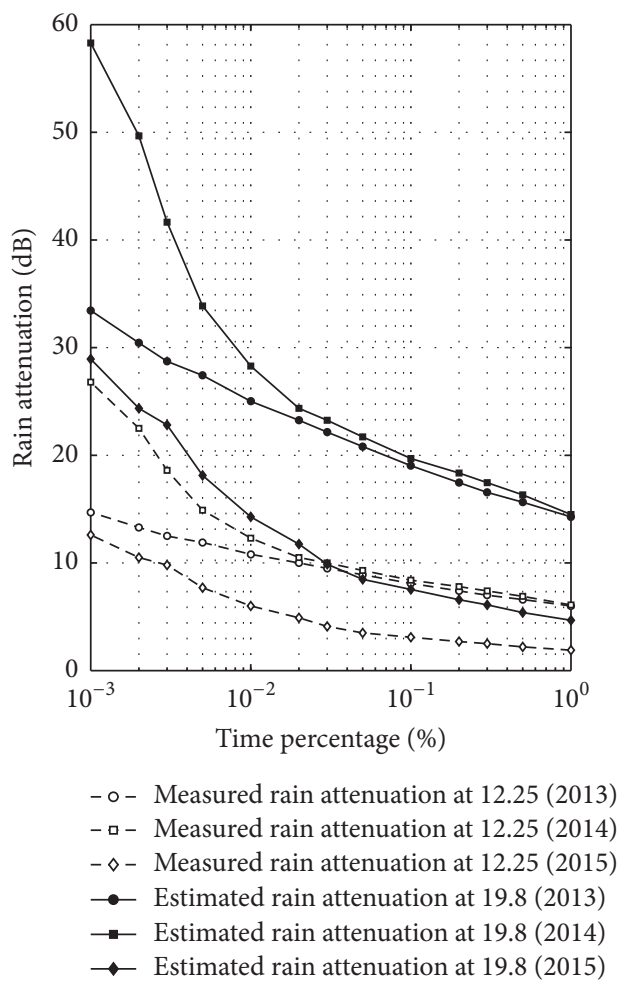

FIGURE 10: Cumulative distribution of rain attenuation obtained after frequency scaling for $19.8 \mathrm{GHz}$ [20].

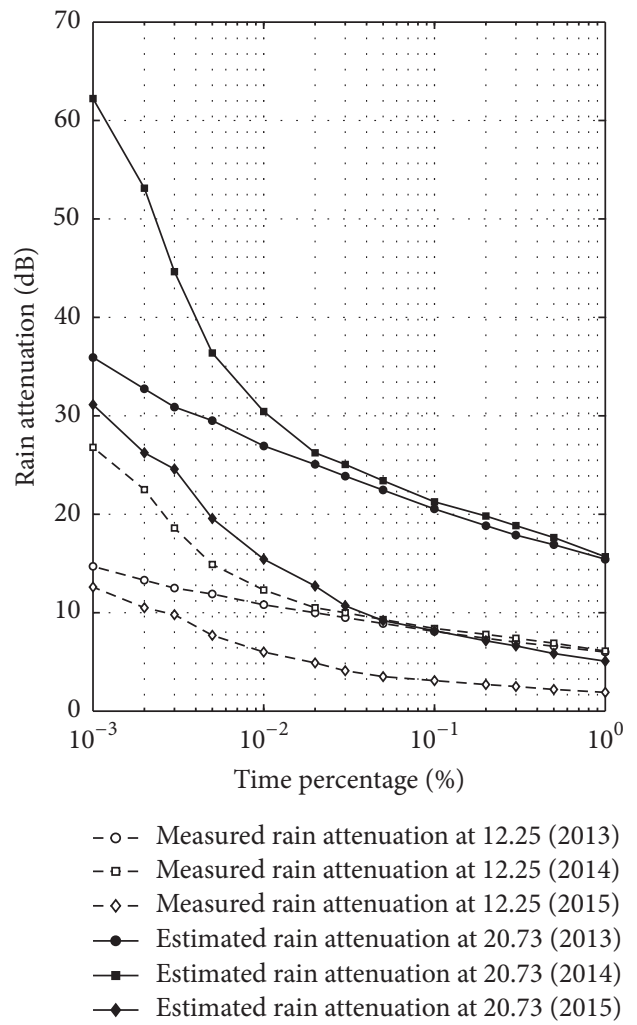

FIGURE 11: Cumulative distribution of rain attenuation obtained after frequency scaling for $20.73 \mathrm{GHz}$ [20].

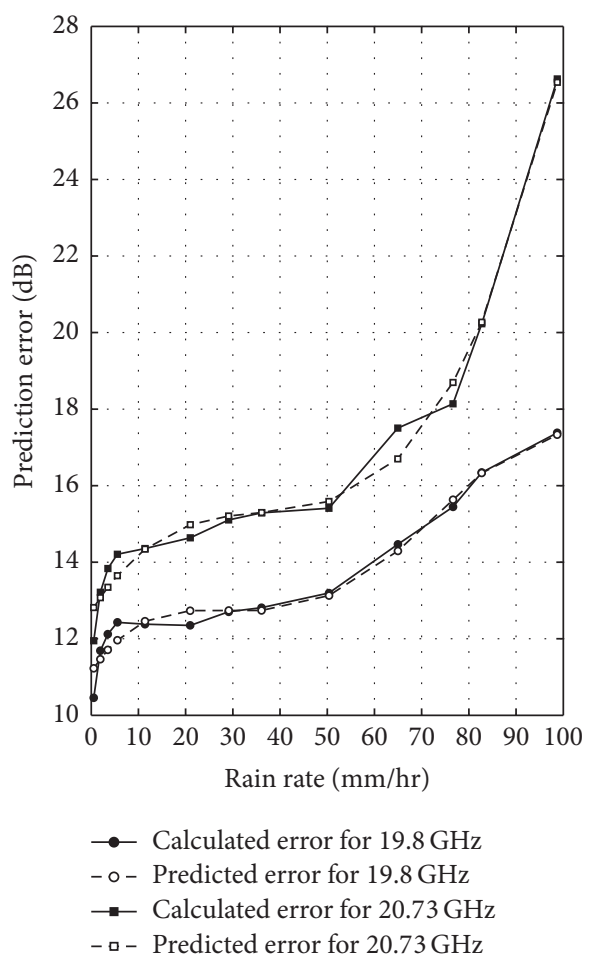

FIGURE 12: Plot between predicted error and 1-minute rainfall rate.

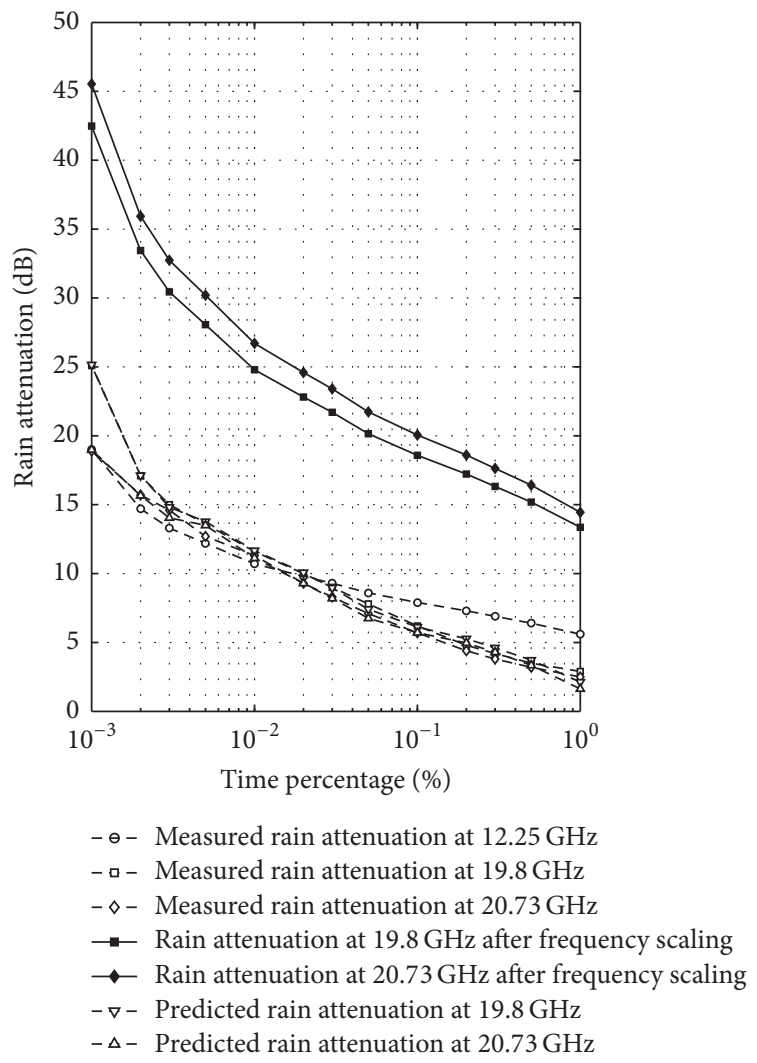

FIGURE 13: Cumulative distribution of calculated and estimated rain attenuation obtained after frequency scaling for combined values [20]. 
TABLE 6: Regression coefficients.

\begin{tabular}{lccccc}
\hline $\begin{array}{l}\text { Frequency } \\
(\mathrm{GHz})\end{array}$ & $a_{1}$ & $a_{2}$ & $a_{3}$ & $a_{4}$ & $a_{5}$ \\
\hline 19.8 & -0.000000601 & 0.0001245 & -0.007713 & 0.1891 & 11.13 \\
20.73 & -0.00000005285 & 0.00005339 & -0.005334 & 0.1971 & 12.71 \\
\hline
\end{tabular}

we considered the absolute values of deviation $\Delta A_{\% p}(\mathrm{~dB})$ which is obtained against the measured rain attenuation. The figure depicts the equal probability plots of rain rate and deviation error $\Delta A_{\% p}$. Investigation of this figure has shown that polynomial of fourth order is best least square regression that fits the prediction error against the 1-minute rain rate distribution which is given as

$$
\Delta A_{\% p}=a_{1} R_{\% p}^{4}+a_{2} R_{\% p}^{3}+a_{3} R_{\% p}^{2}+a_{4} R_{\% p}+a_{5},
$$

where $\Delta A_{\% p}$ is the prediction error and $a_{1}, a_{2}, a_{3}, a_{4}$, and $a_{5}$ are regression parameters whose values depend on frequency and radio path length of the link under consideration. Table 6 shows the values of regression coefficients used for the estimation of prediction errors against the full 1-minute rain rate distribution over $0.001 \% \leq \% p \leq 1 \%$.

Hence, in order to improve rain attenuation prediction approach from the frequency scaling method, it is proposed that the prediction error obtained from (8) needs to be subtracted from the estimation values as derived from frequency scaling approach which is mentioned in the ITU-R P. 618-12.

Figure 13 shows that there is the overestimation for predicted 19.8 and $20.73 \mathrm{GHz}$ links which are obtained from the application of the frequency scaling method. For instance, the calculated rain attenuations at 19.8 and $20.73 \mathrm{GHz}$ links are $6.2,11.6$, and $25.1 \mathrm{~dB} ; 5.7,11.3$, and $18.9 \mathrm{~dB}$, respectively, at $0.1 \%, 0.01 \%$, and $0.001 \%$ of the time and the estimated values are $18.58,24.80$, and $42.48 \mathrm{~dB} ; 20.06,26.71$, and $45.53 \mathrm{~dB}$. Interestingly, this overestimation is decreased and the better estimation is obtained with the subtraction of the prediction error as calculated from (8). The better performance analyses are judged through the error matrices as presented in Table 7.

As noticed from Table 7, the attenuation statistics obtained at 19.8 and $20.73 \mathrm{GHz}$ after applying frequency scaling technique show the higher relative error chances for all time percentages when $0.001 \% \leq p \leq 1 \%$ of the time. On the contrary, the predicted attenuation statistics for both frequencies calculated after subtracting prediction error from the attenuation series calculated with the application of frequency scaling technique as mentioned in ITU-R P. 618-12 generate the lower chances of relative error probabilities. For instance, obtained relative error percentages are $200 \%, 114 \%$, and $69 \% ; 252 \%, 136 \%$, and $141 \%$ for 19.8 and $20.73 \mathrm{GHz}$ under $0.1 \%, 0.01 \%$, and $0.001 \%$ of the time, respectively, from the application of frequency scaling technique whereas the relative error percentage obtained after subtracting prediction error generates $1 \%, 1 \%$, and $0 \% ; 0 \%, 2 \%$, and $0 \%$.

\section{Conclusions}

The rain attenuation and rain rate, collected over three years during 2013-2015 in the 12.25 and $20.73 \mathrm{GHz}$ from Koreasat 6 and $19.8 \mathrm{GHz}$ from COMS1 for Mokdong Station, were analyzed to observe the statistical characteristics. In this paper, the local environmental propagation effects in slantpath attenuation for $\mathrm{Ku}$ and $\mathrm{Ka}$ bands have been investigated. As first approach to this open research problem, a statistical analysis has been proposed to predict the time series of rain attenuation, effective path length, and specific attenuation at $\mathrm{Ku}$ and $\mathrm{Ka}$ band over an earth-space path in South Korea. The measured rain attenuation distribution at $0.01 \%$ of the time in $\mathrm{Ka}$ band is higher than $\mathrm{Ku}$ band and the rain rate is found to be $50.35 \mathrm{~mm} / \mathrm{hr}$. It has been found that the empirically derived $k$ and $\alpha$ show suitability in the calculation of attenuation series for all time percentages when $0.001 \% \leq$ $p \leq 1 \%$ of the time against the measured values. The predictive capabilities of the models are judged through the relative error analyses, standard deviation, root mean square, and chi-square values as well as the recommendation of ITU-R P.311-15 method. Thus, the paper presents the comparison of the measured data with the existing ITU-R rain attenuation prediction model for slant-path communication and shows suitable method for the categorization of best fitting approach. Rain attenuation predictions are made for a number of transmission paths at a fixed set of probability levels. However, it should be noted that the results are valid for these particular climates, and their feasibility for other regions requires more testing and analyses. On the whole, we can adopt ITU-R P. 618-12 rain attenuation model in South Korea for better prediction of rain attenuation until the sufficient database of rain attenuation and rain rate from other locations becomes available. In addition, frequency scaling schemes are analyzed as per the recommendation of ITU-R P. 618-12 where the validation of this approach is performed by comparing with experimental data through error matrices where the suitable parameters are derived for better estimation of the prediction error.

Overall, based on such results, the contribution describes some preliminary steps aiming at devising appropriate methodology for prediction of rain attenuation affecting earth-space communication link. However, more observations are needed from different locations to provide a statically reliable estimation. Hence, the analyses of prominent rain attenuation methods make the $\mathrm{Ku}$ and $\mathrm{Ka}$ bands spectrum studies for broadband satellite applications and network centric systems.

\section{Competing Interests}

The authors declare that they have no competing interests.

\section{Acknowledgments}

The authors want to extend their thankfulness towards National Radio Research Agency (RRA) for providing and supporting them with the valuable database of satellite system. 







\section{References}

[1] J. S. Mandeep, S. I. S. Hassan, and M. F. Ain, "Rain rate conversion for various integration time for equatorial and tropical climates," International Journal of Satellite Communications and Networking, vol. 26, no. 4, pp. 329-345, 2008.

[2] K. C. Robert, Electromagnetic Wave Propagation through Rain, John Wiley \& Sons, 1996.

[3] Z. B. Hasanuddin, K. Fujisaki, K. Ishida, and M. Tateiba, "Measurement of $\mathrm{Ku}$-band rain attenuation using several VSATs in Kyushu Island, Japan," IEEE Antennas and Wireless Propagation Letters, vol. 1, pp. 116-119, 2002.

[4] J. E. Allnutt and F. Haidara, "Ku-band diurnal fade characteristics and fade event duration data from three, two-year, Earth-space radiometric experiments in Equatorial Africa," International Journal of Satellite Communications, vol. 18, no. 3, pp. 161-183, 2000.

[5] B. R. Elbert, Introduction to Satellite Communication, Artech House, 2008.

[6] L. J. Ippolito Jr., Satellite Communications Systems Engineering: Atmospheric Effects, Satellite Link Design and System Performance, vol. 6, John Wiley \& Sons, 2008.

[7] Jr. Ippolito and J. Louis, "Rain attenuation prediction methods," in Radiowave Propagation in Satellite Communications, pp. 6492, Springer, Amsterdam, The Netherlands, 1986.

[8] P. Timothy, W. C. Bostian, and J. E. Allnutt, Satellite Communication, John Wiley \& Sons, New York, NY, USA, 2nd edition, 2003.

[9] J. S. Ojo, M. O. Ajewole, and S. K. Sarkar, "Rain rate and rain attenuation prediction for satellite communication in $\mathrm{Ku}$ and Ka bands over Nigeria," Progress in Electromagnetics Research B, vol. 5, pp. 207-223, 2008.

[10] J. S. Mandeep and J. E. Allnutt, "Rain attenuation predictions at Ku-band in South East Asia countries," Progress in Electromagnetics Research, vol. 76, pp. 65-74, 2007.

[11] J. S. Mandeep and K. Tanaka, "Effect of atmospheric parameters on satellite link," International Journal of Infrared and Millimeter Waves, vol. 28, no. 10, pp. 789-795, 2007.

[12] "Propagation data and prediction methods required for the design of Earth-space telecommunication systems," ITU-R P. 618-12, 2015.

[13] S. Shrestha, J. J. Park, and D. Y. Choi, "Rain rate modeling of 1-min from various integration times in South Korea," SpringerPlus, vol. 5, article 433, 2016.

[14] S. Sujan, P. Jung-Jin, S. W. Kim, J. J. Kim, J. H. Jung, and D. Y. Choi, 1-Minute Rain Rate Derivation from Various Integration Times in South Korea, Korean Institute of Next Generation Computing, Bangkok, Thailand, 2016.

[15] S. Sujan and D.-Y. Choi, "Proposed one-minute rain rate conversion method for microwave applications in South Korea," Journal of Information and Communication Convergence Engineering, vol. 14, no. 3, 2016.

[16] D. Y. Choi, "Rain attenuation prediction model by using the 1hour rain rate without 1-minute rain rate conversion," Journal of Computer Science and Network Security, vol. 6, pp. 130-133, 2006.

[17] D. Y. Choi, J. Y. Pyun, S. K. Noh, and S. W. Lee, "Comparison of measured rain attenuation in the $12.25 \mathrm{GHz}$ band with predictions by the ITU-R model," International Journal of Antennas and Propagation, vol. 2012, Article ID 415398, 5 pages, 2012.
[18] S. Sujan and D.-Y. Choi, "Study of rain attenuation in Ka Band for Satellite Communication in South Korea," Journal of Atmospheric and Solar Terrestrial Physics, vol. 148, pp. 53-63, 2016.

[19] National Radio Research Agency (RRA) 767, Bitgaram-ro, Najusi, Jeollanam-do 58217, Republic of Korea, http://rra.go.kr/en/ index.do.

[20] The mathworks, Inc. Protected by U.S. and international patents, http://www.mathworks.com/.

[21] A. I. Yussuff and N. H. H. Khamis, "Rain attenuation prediction model for lagos at millimeter wave bands," Journal of Atmospheric and Oceanic Technology, vol. 31, no. 3, pp. 639-646, 2014.

[22] A. I. Yussuff and N. H. Khamis, "Rain attenuation modelling and mitigation in the tropics: brief review," International Journal of Electrical and Computer Engineering, vol. 2, no. 6, p. 748, 2012.

[23] J. S. Mandeep, R. Nalinggam, and W. B. Ismail, "Analysis of rain attenuation models for South East Asia countries," Journal of Infrared, Millimeter, and Terahertz Waves, vol. 32, no. 2, pp. 233240, 2011.

[24] K. Chakravarty and A. Maitra, "Rain attenuation studies over an earth-space path at a tropical location," Journal of Atmospheric and Solar-Terrestrial Physics, vol. 72, no. 1, pp. 135-138, 2010.

[25] J. S. Mandeep, "Slant path rain attenuation comparison of prediction models for satellite applications in Malaysia," Journal of Geophysical Research: Atmospheres, vol. 114, no. 17, Article ID D17108, 2009.

[26] J. S. Mandeep, "Comparison of rainfall models with Ku-band beacon measurement," Acta Astronautica, vol. 64, no. 2-3, pp. 264-271, 2009.

[27] J. S. Mandeep, S. I. S. Hassan, and K. Tanaka, "Rainfall measurements at Ku-band satellite link in Penang, Malaysia," IET Microwaves, Antennas and Propagation, vol. 2, no. 2, pp. 147-151, 2008.

[28] R. Nalinggam, W. Ismail, M. J. Singh, M. T. Islam, and P. S. Menon, "Development of rain attenuation model for Southeast Asia equatorial climate," IET Communications, vol. 7, no. 10, pp. 1008-1014, 2013.

[29] J. S. Mandeep, "Analysis of rain attenuation prediction models at Ku-band in Thailand," Advances in Space Research, vol. 49, no. 3, pp. 566-571, 2012.

[30] T. Pratt, C. W. Bostian, and J. E. Allnutt, Satellite Communications, John Wiley \& Sons, 2nd edition, 2003.

[31] ITU-R, Specific Attenuation Model for Rain for Use in Prediction Methods, Recommendation P.838-3, ITU-R Recommendations, P Series, Intemational Telecommunications Union, Geneva, Switzerland, 2005.

[32] K. S. Choi, J. H. Kim, D.-S. Ahn, N. H. Jeong, and J. K. Pack, "Trends in rain attenuation model in satellite system," in Proceedings of the 13th International Conference on Advanced Communication Technology: Smart Service Innovation through Mobile Interactivity (ICACT '11), pp. 1530-1533, IEEE, Pyeongchang-gun, Republic of Korea, February 2011.

[33] J. X. Yeo, Y. H. Lee, and J. T. Ong, "Rain attenuation prediction model for satellite communications in tropical regions," IEEE Transactions on Antennas and Propagation, vol. 62, no. 11, pp. 5775-5781, 2014.

[34] ITU-R, Rain Height Model for Prediction Methods, Recommendation P.839-4, ITU-R Recommendations, P Series, International Telecommunications Union, Geneva, Switzerland, 2013.

[35] W. L. Stutzman and K. M. Yon, "Simple rain attenuation model for earth-space radio links operating at 10-35 GHz," Radio Science, vol. 21, no. 1, pp. 65-72, 1986. 
[36] N. M. N. M. Downie and R. W. Heath, Basic statistical methods, No. 04; HA29, D6, 1983.

[37] International Telecommunication Union, "Acquisition, presentation and analysis of data in studies of radiowave propagation," ITU-R P. 311-15, International Telecommunication Union, Geneva, Switzerland, 2013. 


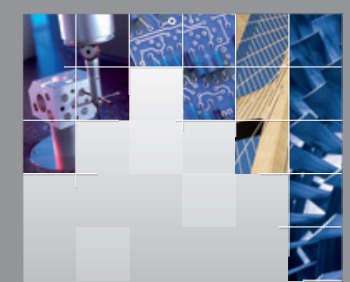

\section{Enfincering}
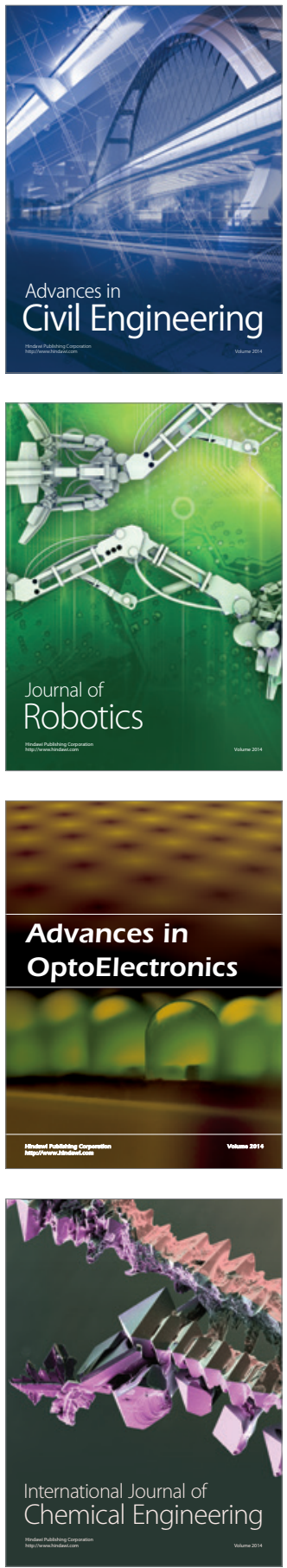

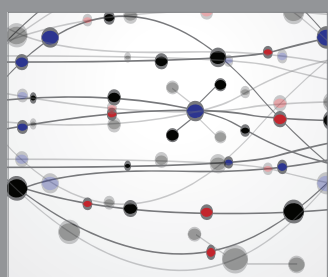

The Scientific World Journal

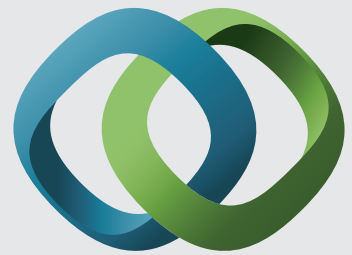

\section{Hindawi}

Submit your manuscripts at

https://www.hindawi.com
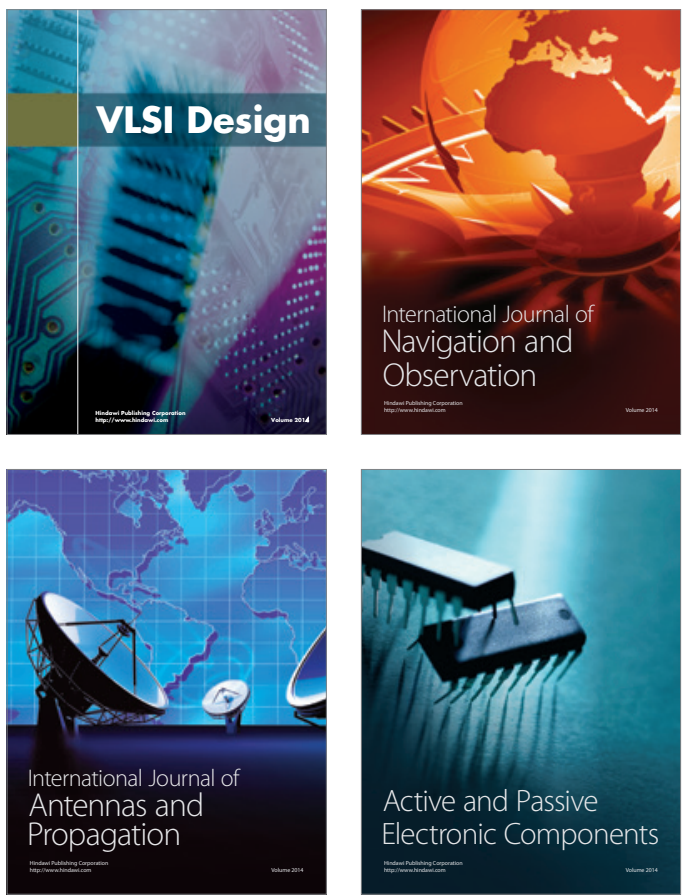
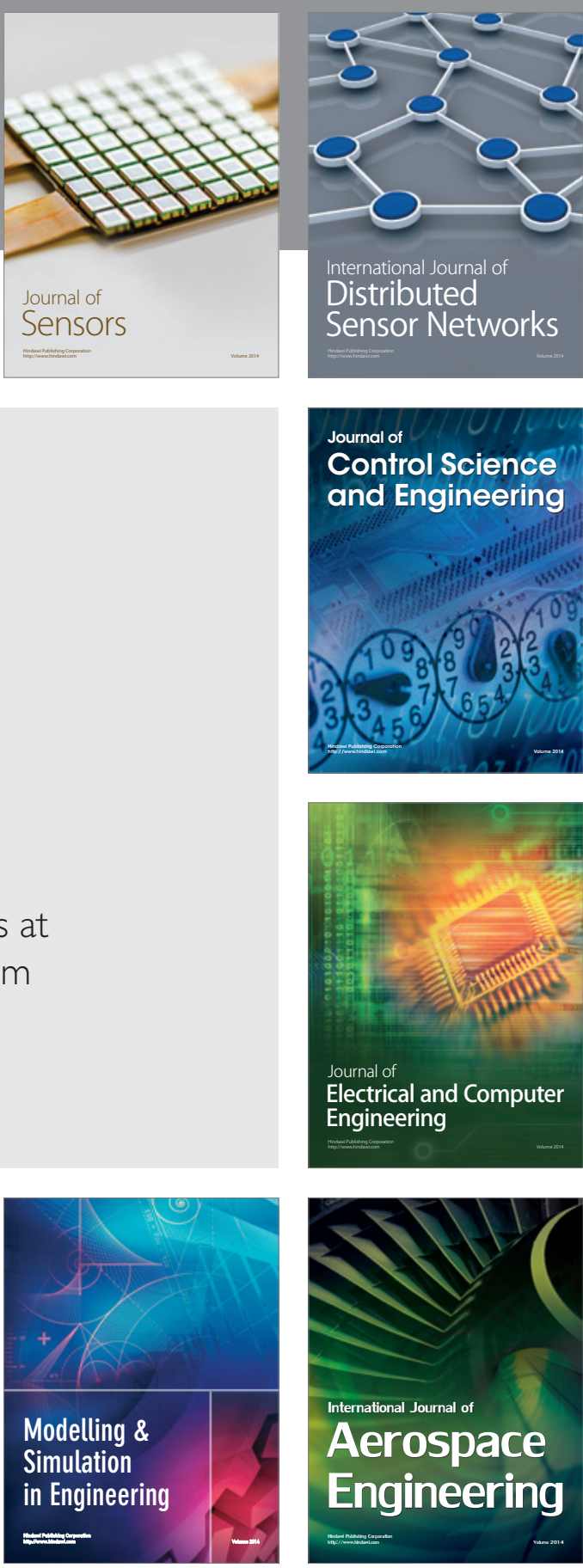

International Journal of

Distributed

Sensor Networks

$-$

Joumal of

Control Science

and Engineering
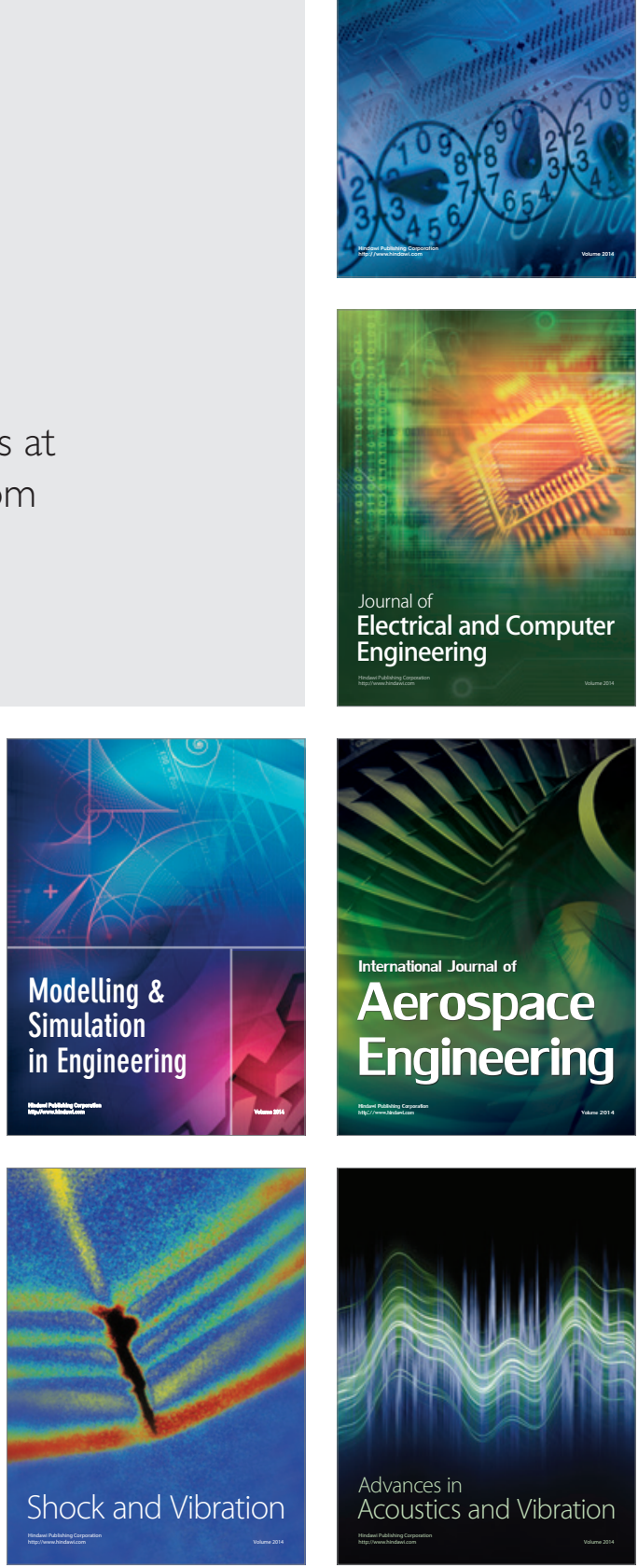